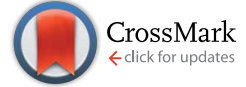

Cite this: RSC Adv., 2017, 7, 14430

Received 26th October 2016 Accepted 6th February 2017

DOI: 10.1039/c6ra25832h

rsc.li/rsc-advances

\section{Enhanced growth and osteogenic differentiation of MC3T3-E1 cells on Ti6Al4V alloys modified with reduced graphene oxide $\uparrow$}

\begin{abstract}
Xiaojing Li, ${ }^{a}$ Kaili Lin ${ }^{\mathrm{b}}$ and Zuolin Wang ${ }^{\star a}$
Graphene and its derivatives, including graphene oxide (GO) and reduced graphene oxide ( $\mathrm{rGO}$ ), have been considered as promising candidates in tissue regeneration. However, there is little information about their use as dental implant coating materials. In the present study, we fabricated an rGO coating on Ti6Al4V alloys. Then, the effect of the rGO coating on the growth and osteogenic differentiation of MC3T3-E1 cells was investigated. Cell culture results showed that the rGO coating apparently stimulated cell adhesion and proliferation, and enhanced the growth and osteogenic differentiation of MC3T3-E1 cells on Ti6Al4V implants. Our studies demonstrate that the rGO-Ti substrate appears to be biocompatible and has osteoinductive potential, which suggests that rGO might be a potential coating material for promoting the osteogenic properties of titanium alloy dental implants.
\end{abstract}

\section{Introduction}

Dental implants have been widely used for restoring missing teeth due to its ability to protect adjacent teeth, high predictability of success, and so on. ${ }^{\mathbf{1 - 4}}$ Titanium and medical-grade Ti6Al4V alloy are the most popular materials, and have been widely used to fabricate dental implants owing to their favorable mechanical properties and intrinsic ability for promoting osseointegration, among other characteristics. ${ }^{5-8}$ The main problem in dental implant therapy lies in a poor and delayed osseointegration, which might lead to failure of the dental implant therapy. ${ }^{9-11}$ The success rate of dental implants significantly depends on the osseointegration ability of the implants. ${ }^{\mathbf{1 2 , 1 3}}$ Essentially, the surface characteristics of titanium implants play an important role on the osseointegration at the tissue-implant interface. ${ }^{14-16}$ Thus, several studies have been focused on the effect of implant surface characteristics on the osseointegration between dental implant and bone tissue. ${ }^{17-19}$ The surface characteristics may apparently affect the hydrophilicity, absorption of proteins, cell attachment, and so on. Therefore, modifying the implant surface may help to improve osseointegration at the tissue-implant interface and maximize the success rate of dental implant therapy. ${ }^{\mathbf{2 0 - 2 2}}$ Although there

${ }^{a}$ Shanghai Engineering Research Center of Tooth Restoration and Regeneration, Department of Oral Implant, School of Stomatology, Tongji University, Shanghai, 200072, China. E-mail: zuolin@tongji.edu.cn; Fax: +86-21-66524025; Tel: +86-2166313725

${ }^{b}$ Shanghai Engineering Research Center of Tooth Restoration and Regeneration, School of Stomatology, Tongji University, Shanghai, 200072, China

† Electronic supplementary information (ESI) available. See DOI: $10.1039 / \mathrm{c} 6 \mathrm{ra} 25832 \mathrm{~h}$ are various new materials for dental implant surface coatings, to date, none of them can satisfy all the criteria for a suitable implant surface coating. Therefore, in order to achieve a better osseointegration in clinical applications, it is crucial to develop a new implant coating material that enhances the osseointegration ability of implants.

Graphene is an atomic-thin carbon material with a twodimensional structure, which possesses unique electric, thermal, mechanical and optical properties. ${ }^{23-25}$ Owing to its various advantages, graphene has been used as a promising material in various fields, such as tissue engineering, nanoelectronics and anti-bacterial papers. ${ }^{26-29}$ Recently, graphenebased materials have attracted great attention owing to their remarkable properties and wide applications in the biomedical field. ${ }^{30-32}$ In addition, its derivatives, graphene oxide (GO) and reduced graphene oxide ( $\mathrm{rGO}$ ), might play a vital role in the development of nanocarriers for drug and gene delivery, cell imaging, and scaffolds for tissue engineering, etc. ${ }^{33-37}$ Reduced graphene oxide, rGO, can be prepared by reduction of GO with specific reducing agents under certain conditions. ${ }^{38-41}$ Owing to the reduction of some special $\pi-\pi$ chemical interactions, rGO exhibits certain better physical and chemical properties than graphene and GO. It has been reported that rGO could affect cell viability, antibacterial activity and osteogenic differentiation in different ways. ${ }^{42,43}$ Recent studies also showed that the rGO coating or modification could enhance the growth and osteogenic differentiation of MC3T3-E1 cells or human mesenchymal stem cells (hMSCs) on collagen, chitosan and hydroxyapatite, etc., ${ }^{\mathbf{4 - 4 6}}$ which suggests that rGO might have great potential as a surface modification material for dental implants. In summary, the rGO coating may impart enhanced biological properties to Ti6Al4V substrates, improving osteogenic differentiation. 
To verify the hypothesis that the rGO coating might possess better biological properties and promote osteogenic differentiation of osteoblast cells (MC3T3-E1), we fabricated rGO-coated Ti6Al4V substrates for dental implant applications. Then, we evaluated the effects of the rGO coating on cell attachment, proliferation and osteogenic differentiation of MC3T3-E1 cells.

\section{Experimental}

\section{Fabrication and characterization of the rGO coating on the Ti6Al4V substrates}

Titanium alloy substrates were successively cleaned by ultrasonication with acetone, ethanol and ultrapure water. In order to introduce positively-charged amine groups on the surface of the titanium alloy, this was immersed in $3 \%$ solution of (3-aminopropyl)-triethoxysilane (APTES) for one hour. ${ }^{47}$ Then, it was washed in ethanol and distilled water successively. A graphene oxide (GO) dispersion with three different concentrations of $0.25,0.5$ and $1.0 \mathrm{mg} \mathrm{ml}^{-1}$ was spin-coated onto the titanium alloy substrates at a speed of $600 \mathrm{rpm}$ for $6 \mathrm{~s}$ and then $1000 \mathrm{rpm}$ for $10 \mathrm{~s}$ to obtain a uniform GO coating. Finally, rGO-coated titanium alloy (rGO-Ti) was obtained by heating the GOcoated substrate at a temperature of $200{ }^{\circ} \mathrm{C}$ for $2 \mathrm{~h}$.

The surface morphology and elemental analysis of rGO-Ti was characterized by scanning electron microscopy (S-4800, Hitachi, Japan). The rGO coating was also analyzed by Raman spectroscopy (Renishaw, inVia, England). The BrunauerEmmett-Teller (BET) surface area, roughness and hydrophilicity of the substrate after coating with rGO were also evaluated.

\section{Cytotoxicity of the rGO coating}

To assess the cytotoxicity of the rGO coating towards MC3T3-E1 cells, the cell viability after seeding on the substrates was determined with the Live/Dead Double Staining kit (Dojindo, Kumamoto, Japan), used according to the manufacturer's instructions. First, the rGO-Ti and Ti substrates were autoclaved at $121{ }^{\circ} \mathrm{C}$ for $25 \mathrm{~min}$, followed by UV irradiation for 2 hours. Then, MC3T3-E1 cells were cultured on each rGO-Ti and Ti substrates at a density of $2 \times 10^{4}$ cells per well for 3 days at $37^{\circ} \mathrm{C}$. Following the manufacturer's instruction, live cells were stained fluorescent green with Calcein AM, while dead cells were stained fluorescent red with propidium iodide (PI). Then, cells were examined using a fluorescence microscope (Nikon ECLIPSE 80i, Nikon, Japan) and were counted with the Image J software.

\section{Cell adhesion and morphology of MC3T3-E1 cells on the rGO coating}

MC3T3-E1 cells were seeded on the rGO-Ti and Ti substrates at a density of $2 \times 10^{4}$ cells per well and cultured for $24 \mathrm{~h}$. Then, the substrate was gently washed with phosphate-buffered solution (PBS) for 5 minutes and subsequently fixed at $4{ }^{\circ} \mathrm{C}$ with $2.5 \%$ glutaraldehyde solution for $1 \mathrm{~h}$. After that, substrates were gently rinsed with PBS 3 times and then dehydrated with ethanol in increasing concentrations (50, 70, 80, 90, 95 and $100 \%$ ) for $10 \mathrm{~min}$ and dried. Afterwards, the samples were sputter-coated with gold and the adhesion and morphology of MC3T3-E1 cells on the different substrates was observed with a scanning electron microscope (S4800, Hitachi, Japan).

Cell morphology was observed with a confocal laser scanning microscope (Nikon, Japan). First, MC3T3-E1 cells were seeded on rGO-Ti and Ti substrates at a density of $2 \times 10^{4}$ cells per well and cultured for $24 \mathrm{~h}$. Then, the substrate was gently washed with phosphate-buffered solution (PBS) and fixed at $4{ }^{\circ} \mathrm{C}$ with $2.5 \%$ glutaraldehyde solution for $1 \mathrm{~h}$. Moreover, cells were treated with $0.1 \%$ Triton-X100 for $5 \mathrm{~min}$. The actin cytoskeleton of MC3T3-E1 cells was stained with $50 \mu \mathrm{g} \mathrm{ml} \mathrm{m}^{-1}$ PhalloidinTRITC (Sigma, USA) for $40 \mathrm{~min}$. Cell nuclei were stained blue with 2-(4-amidinophenyl)-6-indolecarbamidine dihydrochloride (DAPI, Sigma, USA). Afterwards, the cell skeleton was examined with a confocal laser scanning microscope (Nikon, Japan).

\section{Cell proliferation on the rGO coating}

To evaluate the effect of the rGO-coated titanium alloy substrates on the proliferation of MC3T3-E1 cells, the Cell Counting Kit-8 (CCK-8) was used according to the instructions (Dojindo, Kumamoto, Japan). Briefly, titanium alloy substrates with and without rGO coating were placed in 24-well plates. Then, MC3T3-E1 cells were seeded on the rGO-Ti and Ti substrates at a density of $2 \times 10^{4}$ cells per well and cultured for 1,3 and 7 days at $37^{\circ} \mathrm{C}$. The culture medium was changed every other day. At the selected time point, the sample was transferred to a new 24-well plate and CCK-8 was added to the culture medium at a ratio of $1: 10$ and incubated for $3 \mathrm{~h}$ at $37{ }^{\circ} \mathrm{C}$. Finally, the absorbance at $450 \mathrm{~nm}$ was measured with a microplate reader (Tecan infinite M200, Tecan Inc., Switzerland).

\section{Mineralized nodule formation}

In order to detect and quantify calcium in the mineralized nodules, cells were treated with alizarin red staining (ARS) solution on day $14 .^{48}$ The cells cultured on different substrates for 14 days were washed with PBS, fixed with $70 \%$ ethanol for 30 minutes, and stained with alizarin red solution for 30 minutes at $37^{\circ} \mathrm{C}$. Then, the titanium substrates were washed with PBS three times to remove the non-specific staining. Subsequently, the mineralized nodule was dissolved with $10 \%$ cetylpyridinium chloride solution for 30 minutes with gentle shaking, and the absorbance at $562 \mathrm{~nm}$ was measured with a microplate reader ${ }^{\mathbf{4 9}}$ (Tecan infinite M200, Tecan Inc., Switzerland).

\section{Alkaline phosphatase (ALP) activity}

To evaluate the effect of the rGO-coated titanium alloy substrates on the osteogenic differentiation of MC3T3-E1 cells, the ALP activity was determined. In a 24-well plate, MC3T3-E1 cells were seeded on the rGO-Ti and Ti substrates at a density of $2.0 \times 10^{4}$ cells per well. After induction for 3 and 7 days, cells were gently rinsed with PBS and lysed with $200 \mu$ of $1 \%$ TritonX100 for $30 \mathrm{~min}$. Afterwards, cell lysates were centrifuged at $12000 \mathrm{rpm}$ at $4{ }^{\circ} \mathrm{C}$ for $10 \mathrm{~min}$ to obtain a supernatant. Then, ALP activity was measured with a commercial ALP activity assay kit (Jiancheng Technology, Nanjing, China) following the 
manufacturer's instructions. The total protein concentration was measured with the BCA Protein Quantification Assay Kit (KeyGEN BioTECH Inc., Nanjing, China). Finally, ALP activity was calculated using $p$-nitrophenol as a standard, and results were expressed as ALP units per $g$ of protein.

\section{RNA isolation and real-time PCR analysis}

In order to determine the effect of the rGO coating on the osteogenic differentiation of MC3T3-E1 cells, in a 24-well plate, cells were seeded on rGO-Ti and Ti substrates at a density of 2.0 $\times 10^{4}$ cells per well and cultured at $37{ }^{\circ} \mathrm{C}$ in a $5 \% \mathrm{CO}_{2}$ atmosphere. After induction for 7 and 14 days, the total RNA of MC3T3-E1 cells was isolated with Trizol (Roche, Basel, Switzerland). Then, mRNA was reversed to cDNA using a Transcriptor First Strand cDNA Synthesis kit (Roche, Basel, Switzerland) and the required cDNA was used for RT-qPCR. Osteogenic-related gene expression, such as Runt-related transcription factor 2 (Runx2), osteopontin (OPN), osteocalcin (OCN), and bone sialoprotein (BSP), was assessed by real-time polymerase chain reaction (RT-PCR). The target genes were normalized against the GAPDH level. The primer sequences used in this study are listed in Table 1. Real-time PCR was performed with a FastStart Universal SYBR Green Master kit (Roche, Basel, Switzerland) in a real-time PCR System (LightCycler®96, Roche, Switzerland).

\section{Statistical analysis}

Data are shown as the mean \pm standard deviation (SD). Data analysis was performed by one-way ANOVA, followed by the Student-Newman-Keuls test. Data with $P<0.05$ were considered statistically significant.

\section{Results}

\section{Fabrication and characterization of the rGO coating on Ti6Al4V substrates}

Microscopy images of the Ti6Al4V and rGO-Ti substrates are displayed in Fig. S1. $\dagger$ Substrates showed a dark background after coating with rGO. As shown in Fig. 1 and 2, rGO coatings were characterized by SEM and Energy Dispersive X-ray Spectroscopy (EDX). Comparing with the images of the original Ti6Al4V

Table 1 Primer sequences used in this study

\begin{tabular}{lll}
\hline Gene & Direction & Sequence $5^{\prime}-3^{\prime}$ \\
\hline \multirow{2}{*}{ GAPDH } & Forward & CATGTTCCAGTATGACTCCACTC \\
& Reverse & GGCCTCACCCCATTTGATGT \\
Runx2 & Forward & CGCCCCTCCCTGAACTCT \\
& Reverse & TGCCTGCCTGGGATCTGTA \\
OCN & Forward & CAGCGGCCCTGAGTCTGA \\
& Reverse & GCCGGAGTCTGTTCACTACCTTA \\
OPN & Forward & GCGGTGAGTCTAAGGAGTCCC \\
& Reverse & TGATCAGAGGGCATGCTCAG \\
BSP & Forward & CCGGCCACGCTACTTTCTT \\
& Reverse & TGGACTGGAAACCGTTTCAGA
\end{tabular}

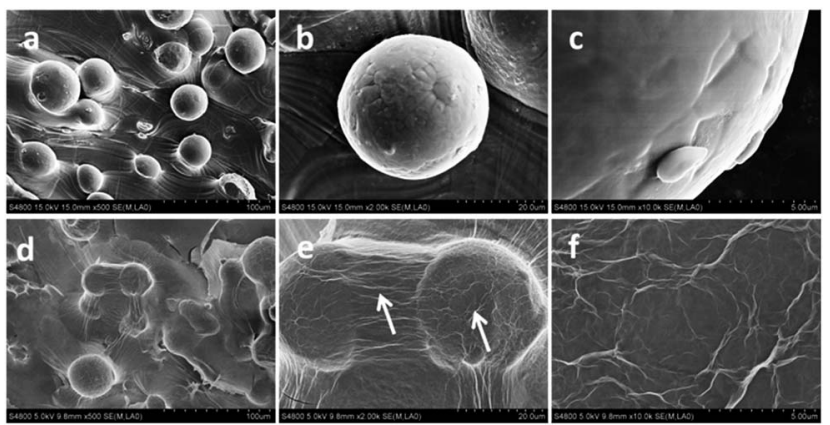

Fig. 1 SEM images of the Ti6Al4V substrate $(a-c)$ and the $r G O-T i$ substrates $(d-f)$ at different magnifications. The white arrows indicate the rGO coating on the Ti6Al4V substrates.

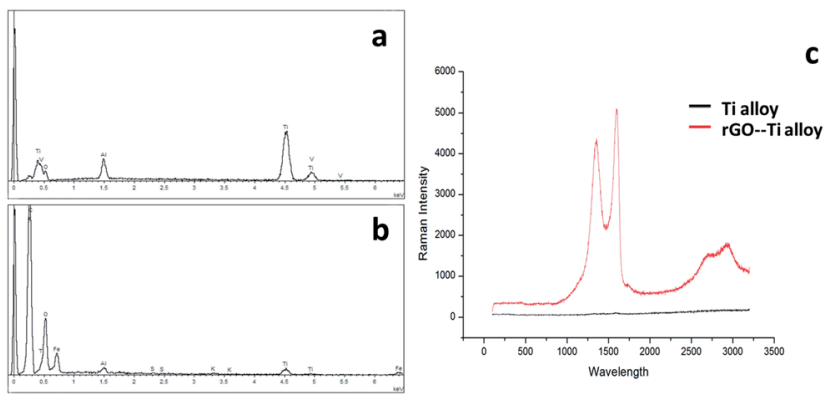

Fig. 2 EDX and Raman spectra of the rGO film coated on the substrates: (a) elemental analysis of the non-coated substrate; (b) elemental analysis of rGO-coated Ti6Al4V; (c) Raman spectra of the rGO film coated on the Ti6Al4V substrate.

substrates (Fig. 1a-c), the SEM images of rGO-Ti revealed a uniform rGO film coating with some wrinkles on the titanium alloy substrates. From the SEM image, the thickness of the rGO coating was determined to be approximately $0.2 \mu \mathrm{m}$ (Fig. S2 $\dagger$ ). The EDX analysis (Fig. 2b) showed a significant increase in the carbon content compared with the pure titanium alloy substrates, which also suggested the presence of rGO coating on the titanium alloy substrates. To further confirm the presence of rGO, Raman spectroscopy was performed to detect the special D and $\mathrm{G}$ bands of rGO. As it can be seen in Fig. 2c, the Raman spectrum of the rGO-Ti substrates shows two prominent peaks at 1356 and $1598 \mathrm{~cm}^{-1}$, attributed to the typical D and $\mathrm{G}$ bands of reduced graphene oxide, respectively, with a $\mathrm{D} / \mathrm{G}$ ratio of 0.84 .

The BET surface area measurements showed that the rGO coating increased the specific surface area, and the specific surface area increased with the increase in the concentration of the rGO coating (Table $\mathrm{S} 1 \dagger$ ). The roughness measurement results also showed that the roughness decreased with the increase in the concentration of the rGO coating (Table S2 $\dagger$ ). The hydrophilicity of the non-coated Ti alloy and rGO-coated substrates was also evaluated (Fig. S3a-d $\dagger$ ). However, there was no significant differences in the contact angles among the four different substrates (Fig. S3B $\dagger$ ).

\section{Effect of the rGO coating on cell cytotoxicity}

As shown in Fig. 3, after 3 days of culture, the cell viability of MC3T3-E1 cells was higher on the rGO-coated samples than on 
A
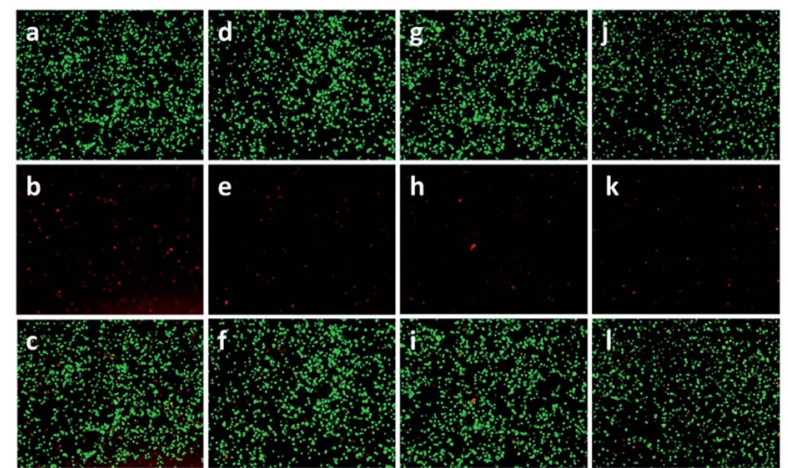

B

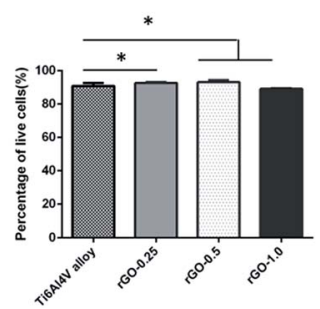

Fig. 3 Cell viability after incubation for 3 days. (A) Live/dead doublestaining of MC3T3-E1 cells cultured on the pristine Ti alloy substrate (a-c), $0.25 \mathrm{mg} \mathrm{ml}^{-1} \mathrm{rGO}$-coated substrate (d-f), $0.5 \mathrm{mg} \mathrm{m}^{-1} \mathrm{rGO}$ coated substrate $(\mathrm{g}-\mathrm{i})$, and $1.0 \mathrm{mg} \mathrm{m}^{-1} \mathrm{rGO}$ coated substrate $(\mathrm{j}-\mathrm{l})$. (B) Live cell percentages on the $\mathrm{Ti}$ and $\mathrm{rGO}$-Ti substrates. The symbol * denotes significant differences among substrates $(* p<0.05)$.

the pristine Ti6Al4V substrate. Cell viability, shown as the ratio of live to dead cells, was evaluated by one-way ANOVA, followed by the Student-Newman-Keuls test; it was determined to be $90.90 \% \pm 1.77 \%, 92.59 \% \pm 0.56 \%, 93.40 \% \pm 0.83 \%$ and $89.15 \%$ $\pm 0.40 \%$ for non-coated Ti, $0.25 \mathrm{mg} \mathrm{ml}^{-1}, 0.5 \mathrm{mg} \mathrm{ml}^{-1}$ and $1.0 \mathrm{mg} \mathrm{ml}^{-1} \mathrm{rGO}-\mathrm{Ti}$, respectively. This result demonstrated that the $0.25 \mathrm{mg} \mathrm{ml}^{-1}$ and $0.5 \mathrm{mg} \mathrm{ml}^{-1}$ rGO coatings possessed a good biocompatibility towards MC3T3-E1 cells.

\section{Effect of the rGO coating on MC3T3-E1 cell adhesion}

In order to evaluate the effect of the rGO coating on cell adhesion and morphology, the morphology of the cells cultured on the rGO-Ti and Ti alloy substrates was observed by SEM after incubation for $24 \mathrm{~h}$ (Fig. 4). Compared with the cells cultured on Ti alloy substrates, cells cultured on the rGO-Ti substrates were more spread out, with elongated lamellipodia anchored to the

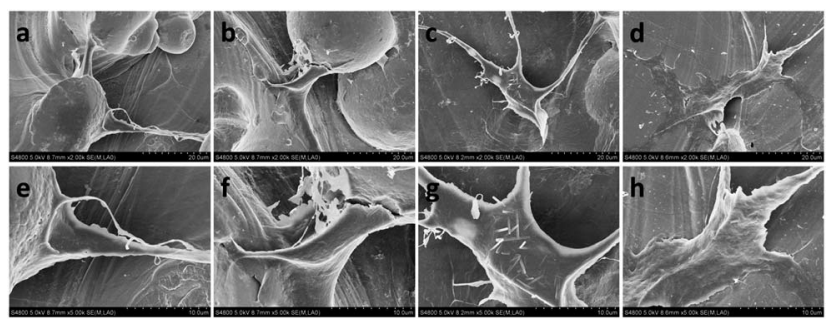

Fig. 4 SEM images of MC3T3-E1 cells cultured on the pristine Ti alloy substrate $(a, e) ; 0.25 \mathrm{mg} \mathrm{ml}^{-1} \mathrm{rGO}$-coated substrate (b, f); $0.5 \mathrm{mg} \mathrm{ml}^{-1}$ rGO-coated substrate (c, g); and $1.0 \mathrm{mg} \mathrm{ml}^{-1} \mathrm{rGO}$-coated substrate (d, h). substrates. This demonstrated that cell attachment was better on the rGO-Ti substrates than on the pristine Ti alloy substrates. In addition, cells cultured on the $0.5 \mathrm{mg} \mathrm{ml}^{-1} \mathrm{rGO}$-Ti substrate displayed a better morphology than those cultured on the other substrates. As for the pure Ti6Al4V substrates, cells were less spread out, which demonstrated that the rGO modification could improve cell adhesion.

In order to compare the attachment and morphology of the MC3T3-E1 cells on the four different substrates, cell structure and morphology were observed by CLSM. As shown in Fig. 5 , the $3 \mathrm{D}$ reconstructed CLSM images reveal that cells cultured on the rGO-coated samples displayed a flatter and more spread-out morphology than those cultured on the pristine $\mathrm{Ti}$ alloy substrate. The results demonstrated that the rGO modification could enhance the adhesion properties of MC3T3-E1 cells, particularly in the samples modified with $0.5 \mathrm{mg} \mathrm{ml}^{-1}$ and $1 \mathrm{mg}$ $\mathrm{ml}^{-1}$ rGO (Fig. 5i and l).

\section{Effect of the rGO coating on the proliferation of MC3T3-E1 cells}

The CCK-8 results showed that there was no significant difference in cell proliferation among the different rGO-coated substrates and the non-coated substrate after 1 day of culture (Fig. 6). However, there was a significant difference in cell proliferation after 3 and 7 days of incubation. At day 3, cells seeded on the $0.5 \mathrm{mg} \mathrm{ml}^{-1}$ rGO-coated substrates achieved a higher cell proliferation than cells seeded on the other substrates $(p<0.05)$. When increasing culture time to 7 days, cells seeded on the $0.5 \mathrm{mg} \mathrm{ml}^{-1}$ rGO-coated substrates also achieved a higher cell proliferation than cells seeded on the other substrates $(p<0.05)$. However, cells seeded on the $1.0 \mathrm{mg}$ $\mathrm{ml}^{-1}$ rGO coating displayed a lower cell proliferation than those seeded on the non-coated substrate $(p<0.05)$.

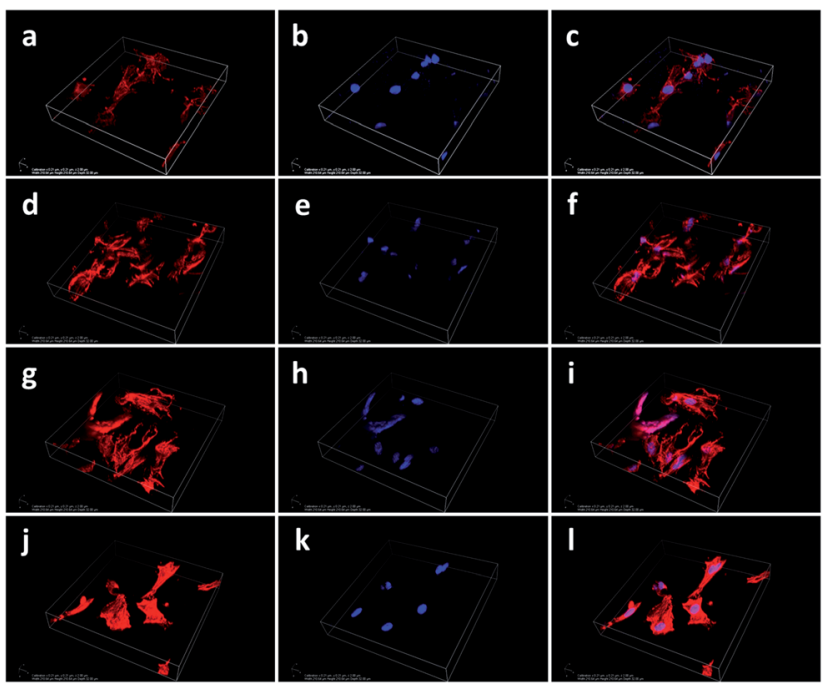

Fig. 5 CLSM images of MC3T3-E1 cells cultured on the Ti alloy substrates $(a-c)$, and on the $0.25 \mathrm{mg} \mathrm{m}^{-1} \mathrm{rGO}$ coating (d-f), $0.5 \mathrm{mg}$ $\mathrm{ml}^{-1} \mathrm{rGO}$ coating $(\mathrm{g}-\mathrm{i})$, and $1.0 \mathrm{mg} \mathrm{m}^{-1} \mathrm{rGO}$ coating $(\mathrm{j}-\mathrm{l})$. Red staining indicates actin cytoskeleton and blue staining represents the cell nuclei. 


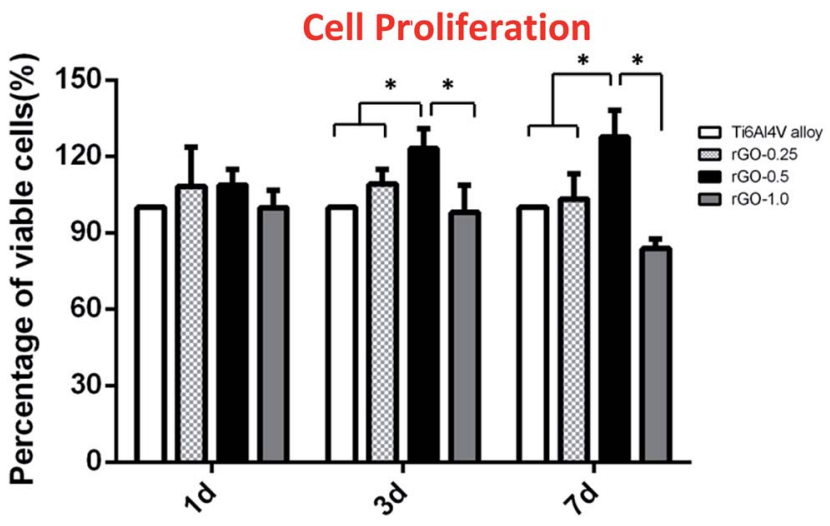

Fig. 6 Cell proliferation of MC3T3-E1 cells cultured on the Ti alloy and rGO-Ti substrates for 1,3 and 7 days; the symbol * denotes significant differences among substrates $(p<0.05)$.

Effect of the rGO coating on mineralized nodule formation

As shown in Fig. 7, cells cultured for 14 days on the $0.5 \mathrm{mg} \mathrm{ml}^{-1}$ rGO coating displayed a higher degree of matrix mineralization than those cultured on the other substrates $(p<0.05)$. Interestingly, the 0.25 and $1.0 \mathrm{mg} \mathrm{ml}^{-1}$ rGO coatings displayed a similar degree of mineralized nodule formation to the noncoated Ti6Al4V substrates $(p>0.05)$.

Effect of the rGO coating on the alkaline phosphatase (ALP) activity of MC3T3-E1 cells

As shown in Fig. 8, cells cultured for 3 days on the $0.25 \mathrm{mg} \mathrm{ml}^{-1}$ and $0.5 \mathrm{mg} \mathrm{ml}^{-1}$ rGO coatings displayed a higher ALP activity than those cultured on the pristine Ti6Al4V and $1.0 \mathrm{mg} \mathrm{ml}^{-1}$ rGO-coated substrates $(p<0.05)$. On increasing culture time to 7 days, cells seeded on the $0.5 \mathrm{mg} \mathrm{ml}^{-1}$ rGO-coated substrates also exhibited a higher ALP activity than those seeded on the other substrates $(p<$ 0.05), while cells cultured on the pristine Ti6Al4V substrate displayed the lowest ALP activity. This demonstrated that rGO may stimulate an early osteoblastic differentiation in MC3T3-E1 cells.

\section{Effect of the rGO coating on the expression of osteogenesis-} related genes

The RT-qPCR results revealed that, after 7 days of culture, the expression of BSP, OCN and Runx2 were significantly higher in

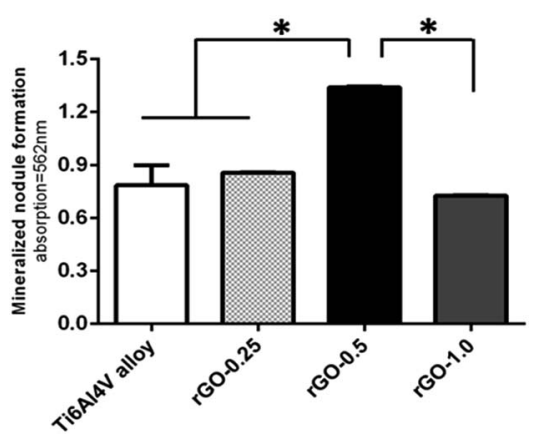

Fig. 7 Assessment of mineralized nodule formation of MC3T3-E1 cells cultured on the Ti alloy and rGO-Ti substrates for 14 days; the symbol * denotes significant differences among substrates $(p<0.05)$.

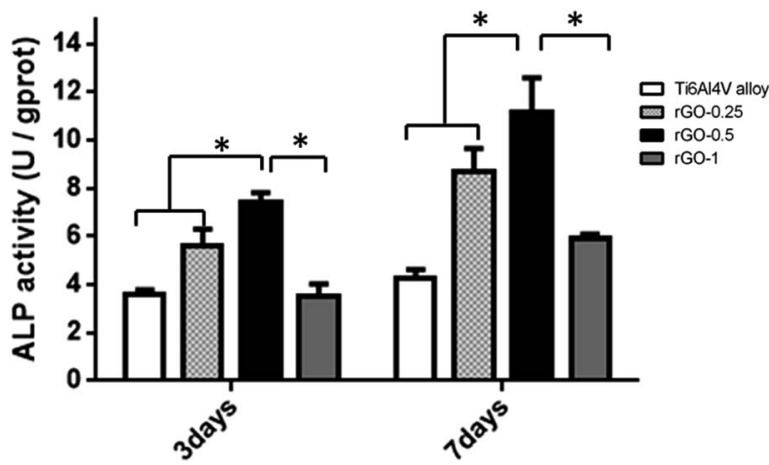

Fig. 8 Assessment of ALP activity in MC3T3-E1 cells cultured on the Ti alloy and rGO-Ti substrates after 3 and 7 days; the symbol * denotes significant differences among substrates $(p<0.05)$.

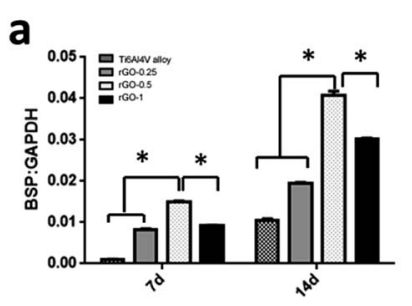

C

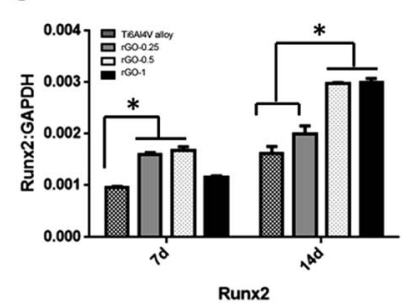

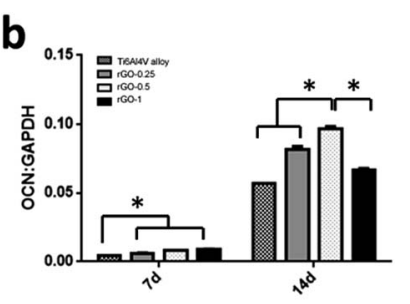

OCN

d

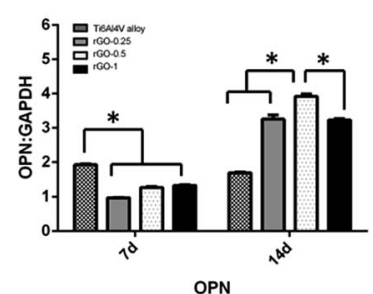

Fig. 9 Real-time PCR analysis of BSP, OCN, Runx2 and OPN mRNA expression in MC3T3-E1 cells cultured on the rGO-Ti and $\mathrm{Ti}$ alloy substrates for 7 and 14 days. Data are presented as the mean $\pm \operatorname{SD}(n=3)$; the symbol *denotes significant differences among substrates $(p<0.05)$.

cells incubated on the rGO-coated substrates, particularly for the $0.5 \mathrm{mg} \mathrm{ml}^{-1}$ rGO coating, than in cells incubated on the pristine Ti6Al4V substrate $(p<0.05)$, as shown in Fig. 9a-c. However, as seen in Fig. 9d, the expression of OPN was significantly higher in cells cultured on the pristine Ti6Al4V substrate than in cells cultured in the rGO-coated substrates $(p<0.05)$. The gene expression level of BSP, OCN, Runx 2 and OPN appeared to increase upon increasing incubation time to 14 days both in the rGO-coated and pristine Ti6Al4V substrates (Fig. 9a-d). Moreover, as seen in Fig. 9a, b and d, the expression of BSP, OCN and OPN was upregulated in cells cultured on the $0.5 \mathrm{mg} \mathrm{ml}^{-1}$ rGO-coated substrate compared to the other substrates $(p<0.05)$, while cells cultured on the $0.5 \mathrm{mg} \mathrm{ml}^{-1}$ and $1.0 \mathrm{mg} \mathrm{ml}^{-1}$ rGO-coated substrates (Fig. 9c) exhibited a similarly higher expression of Runx2 $(p>0.05)$.

\section{Discussion}

It is well-known that the success rate of dental implants depends on the osseointegration at the interface of the dental 
implant and bone tissue. However, osseointegration is a complex biological process that is determined by the physical and chemical characteristics of the dental implant surfaces. ${ }^{50,51}$ Therefore, the modification of dental implant surfaces is critical for accelerating bone formation on dental implants. ${ }^{52}$ At present, dental implant surface modifications include gritblasting, acid etching, microarc oxidation (MAO), and titanium plasma spraying (TPS), among other methods. ${ }^{53,54}$ Currently, the incorporation of coating materials such as hydroxyapatite (HAp) and nanostructured CaP have also been widely used for dental implant surface modifications. However, all these materials lack intrinsic osteoinductivity. Therefore, the improvement of the intrinsic osteoinductivity of implants is important for achieving an excellent osseointegration. Previous studies $^{55}$ suggested that rGO could stimulate the spontaneous osteogenic differentiation of mesenchymal stem cells, and also that rGO might be used as a functional material to modify biomaterials. In this study, we modified Ti6Al4V alloy substrates with an rGO coating via spin-coating technique with an electrostatic interaction to provide an excellent platform for the adhesion, proliferation and osteogenic differentiation of MC3T3-E1 cells. The rGO coating on the Ti6Al4V alloy substrates was characterized by SEM, EDX and Raman spectroscopy. The results displayed a homogenous rGO film coating the substrates, and the presence of rGO was further confirmed from the typical D and $\mathrm{G}$ bands. In addition, the rGO amount in the coating could be facilely tailored by adjusting the GO concentration of the dispersions used for the spin-coating process. Moreover, the BET specific surface area increased at a higher concentration of GO dispersions. In addition, the Ti6Al4V substrate that was coated with rGO exhibited less roughness. Moreover, the hydrophilicity of the non-coated and coated substrates was similar and the rGO coating did not have an adverse effect on it.

The live/dead double staining results revealed a dosedependent decrease in cell viability. There was less red dead cells on the 0.25 and $0.5 \mathrm{mg} \mathrm{ml}^{-1}$ rGO-coated substrates than on the non-coated substrates, which demonstrated a good biocompatibility of the rGO coating for concentrations up to $0.5 \mathrm{mg} \mathrm{ml} \mathrm{m}^{-1}$. A similar trend in cell viability was also found by the CCK- 8 assay. The results of the CCK-8 assay showed that the cells on the rGO-Ti substrates with a concentration of 0.25 and $0.5 \mathrm{mg} \mathrm{ml}^{-1}$ grew faster and achieved a higher proliferation rate than those on the Ti alloy substrates, and the coatings with a concentration of $0.5 \mathrm{mg} \mathrm{ml} \mathrm{m}^{-1}$ exhibited the best cell proliferation. However, the rGO coating with a concentration of $1.0 \mathrm{mg} \mathrm{ml} \mathrm{m}^{-1}$ showed a decrease in cell proliferation compared with the pristine $\mathrm{Ti}$ alloy substrates. $\mathrm{Lee}^{55}$ et al. reported that rGO-coated hydroxyapatite bioceramics could decrease the cytotoxicity of HAp microparticles and achieve a better cell proliferation with lower doses, which is in line with our results. The CLSM and SEM images showed that the MC3T3-E1 cells cultured on rGO-modified substrates exhibited an excellent morphology with cytoplasmic lamellipodia, which confirmed the good biocompatibility of rGO. Kanayama et al. ${ }^{56}$ also stated that rGO-modified collagen scaffolds exhibited a good cytocompatibility, and our results were in accordance with theirs.
The enhanced effect of rGO on cell proliferation and adhesion indicated that rGO may be a friendly and biocompatible material for osteoblasts, which is critical for dental implant coating materials and their successful clinical applications. The excellent cell attachment and proliferation on the rGO-Ti substrate might be attributed to the rapid absorption of protein due to the $\pi-\pi$ stacking between aromatic rings in the rGO coating, thus providing a biocompatible environment for cells to adhere and proliferate that ultimately attracts more cells to adhere on the substrates. However, a high dose of rGO will generate oxidative stress, which may produce toxic and side effects on the cells. ${ }^{56}$

As is known, surface properties of dental implants also have a great impact on cell differentiation. Numerous studies have been focused on the effects of surface properties, including hydrophilicity, morphology and chemical composition, on cell proliferation and differentiation. ${ }^{57,58}$ In our study, mineralized nodule formation, ALP activity and RT-qPCR analysis were conducted to investigate the effect of rGO coating on the osteogenic differentiation of MC3T3-E1 cells. Our results showed that ALP activity was significantly higher in the MC3T3-E1 cells cultured for 3 and 7 days on rGO-coated substrates compared with that of cells cultured on the non-coated substrate. However, cells cultured on the $1.0 \mathrm{mg} \mathrm{ml}^{-1}$ rGO-coated substrate exhibited a lower ALP activity, which may be attributed to activation of a signal pathway that may decrease osteogenic differentiation, unlike in the 0.25 and $0.5 \mathrm{mg} \mathrm{ml}^{-1}$ rGO coating. It is well-known that ALP activity is considered as an early marker of mineralized ECM, which demonstrates that the presence of rGO may stimulate early osteogenic differentiation. ${ }^{59}$ The study of Lee et al. ${ }^{55}$ showed that rGO-coated hydroxyapatite composites could increase ALP activity significantly compared with that of the non-coated control material, which was in accordance with our results. In order to further understand whether the rGO coating could enhance bone mineralization, the mineralized nodule formation was evaluated. The results showed that cells cultured on the rGO coating with a concentration of $0.5 \mathrm{mg} \mathrm{ml}^{-1}$ displayed the highest bone mineralization compared with that of the other substrates. The differentiation of MC3T3-E1 cells was also quantitatively evaluated by RT-qPCR with osteogenic-related makers, including Runx2, BSP, OPN and OCN. The RT-PCR results showed that after 7 days of culture, rGO-Ti induced a higher expression of Runx2, BSP and OCN than the pristine Ti alloy substrate. Upon prolonging culture time to 14 days, a higher expression of Runx2, BSP, OCN and OPN was observed in the cells cultured on the rGO-Ti substrates with different rGO concentrations. The mineralized nodule formation, ALP activity and RT-PCR results confirmed that the rGO modification could enhance osteogenic differentiation in osteoblasts.

The mechanism by which the rGO-Ti substrates could promote cell osteogenic differentiation remains unknown. Indeed, there are many factors, including microstructure, roughness, protein absorption ability and electrostatic interactions that may be attributed to the effects of the rGO coating on the bioactivity of MC3T3-E1 cells. Kanayama et al. ${ }^{56}$ reported that rGO could accumulate higher amounts of $\mathrm{Ca}^{2+}$, which may provide a more favourable environment for cell osteogenic 
differentiation. Essentially, $\pi-\pi$ stacking between the aromatic rings in rGO may also play an important role in promoting protein absorption, which may stimulate cell attachment, proliferation and osteogenic differentiation. Therefore, we speculated that the rGO coating may improve cell attachment, proliferation and osteogenic differentiation of MC3T3-E1 cells by the rapid absorption of serum protein, which could provide a hydrophilic and biocompatible environment for cells. Moreover, Wu et al. ${ }^{60}$ found that GO could enhance osteogenic differentiation by activating the Wnt-related signalling pathway. Zhang et al. ${ }^{61}$ also revealed that GO promoted the osteogenic ability of rBMSCs by activating the Hif- $1 \alpha$ pathway, and further enhanced the expression of BMP-2 via the Erk1/2 signalling pathway. However, the underlying mechanism of enhanced osteogenic differentiation by rGO in this study needs to be studied further, along with some specific signalling pathways.

Taken together, the results indicated that rGO may be considered as a promising coating material for the Ti6Al4V alloy and could promote adhesion, proliferation and osteogenic differentiation in MC3T3-E1 cells.

\section{Conclusions}

In this study, we fabricated rGO coatings on Ti6Al4V alloy substrates and evaluated the osteogenic properties of the coated and non-coated substrates. The results indicated that rGO has a positive effect on the biocompatibility and osteoinductive ability of Ti6Al4V alloy substrates. Our study suggests that rGO may be a promising coating material to improve the osteogenic ability of dental implants.

\section{Acknowledgements}

This study was financially supported by the grants from the National Natural Science Foundation of China (No. 81271110, 81670962), the Natural Science and Technology Support Program (No. 2014BAI04B07) and the Fundamental Research Funds for the Central Universities (No. 20152957) of China.

\section{References}

1 L. Gaviria, J. P. Salcido, T. Guda and J. L. Ong, J. Korean Assoc. Oral Maxillofac. Surg., 2014, 40, 50-60.

2 A. Barfeie, J. Wilson and J. Rees, Br. Dent. J., 2015, 218, E9.

3 O. E. Ogle, Dent. Clin. North Am., 2015, 59, 505-520.

4 E. Anitua, L. Piñas, A. Murias, R. Prado and R. Tejero, Colloids Surf., B, 2015, 130, 173-181.

5 M. Annunziata and L. Guida, Front. Oral Biol., 2015, 17, 6277.

6 X. Y. Liu, P. K. Chu and C. X. Ding, Mater. Sci. Eng., R, 2004, 49-121.

7 Y. Liu, C. Bao, D. Wismeijer and G. Wu, Mater. Sci. Eng., C, 2015, 49, 323-329.

8 G. Jin, H. Qin, H. Cao, S. Qian, Y. Zhao, X. Peng, X. Zhang, X. Liu and P. K. Chu, Biomaterials, 2014, 35, 7699-7713.
9 R. Hayashi, T. Ueno, S. Migita, Y. Tsutsumi, H. Doi, T. Ogawa, T. Hanawa and N. Wakabayashi, J. Dent. Res., 2014, 93, 698-703.

10 S. K. Chuang, L. J. Wei, C. W. Douglass and T. B. Dodson, J. Dent. Res., 2002, 81, 572-577.

11 C. Rungsiyakull, Q. Li, G. Sun, W. Li and M. V. Swain, Biomaterials, 2010, 31, 7196-7204.

12 A. Lugovskoy and S. Lugovskoy, Mater. Sci. Eng., C, 2014, 43, 527-532.

13 P. I. Brånemark, J. Prosthet. Dent., 1983, 50, 399-410.

14 Y. M. Wang, G. J. Du, H. Liu, D. Liu, S. B. Qin, N. Wang, C. G. Hu, X. T. Tao, J. Jiao and J. Y. Wang, Adv. Funct. Mater., 2008, 18, 1131-1137.

15 A. Zareidoost, M. Yousefpour, B. Ghaseme and A. Amanzadeh, J. Mater. Sci.: Mater. Med., 2012, 23, 1479-1488.

16 J. K. Qin, H. Y. He, W. J. Zhang, F. P. Chen and C. S. Liu, RSC Adv., 2016, 6, 51914-51923.

17 S. Tetè, F. Mastrangelo, T. Traini, R. Vinci, G. Sammartino, G. Marenzi and E. Gherlone, Implant Dentistry, 2008, 17, 309-320.

18 C. N. Elias, Y. Oshida, J. H. Lima and C. A. Muller, J. Mech. Behav. Biomed. Mater., 2008, 1, 234-242.

19 K. Anselme and M. Bigerelle, Acta Biomater., 2005, 1, 211222.

20 L. Tack, K. Schickle, F. Böke and H. Fischer, Dent. Mater., 2015, 31, 1169-1179.

21 J. Vlacic-Zischke, S. M. Hamlet, T. Friis, M. S. Tonetti and S. Ivanovski, Biomaterials, 2011, 32, 665-671.

22 N. Jiang, S. S. Zhu, J. H. Li, L. Zhang, Y. M. Liao and J. Hu, RSC Adv., 2016, 6, 49954-49965.

23 C. N. Rao, A. K. Sood, K. S. Subrahmanyam and A. Govindaraj, Angew. Chem., Int. Ed., 2009, 48, 7752-7777.

24 H. S. Jung, Y. J. Choi, J. Jeong, Y. Lee, B. Hwang, J. Jang, J. H. Shim, Y. S. Kim, H. S. Choi, S. H. Oh, C. S. Lee, D. W. Cho and S. K. Hahn, RSC Adv., 2016, 6, 26719-26724. 25 X. Zhou and F. Liang, Curr. Med. Chem., 2014, 21, 855-869. 26 X. Huang, X. Qi, F. Boey and H. Zhang, Chem. Soc. Rev., 2012, 41, 666-686.

27 L. Yan, Y. B. Zheng, F. Zhao, S. Li, X. Gao, B. Xu, P. S. Weiss and Y. Zhao, Chem. Soc. Rev., 2012, 41, 97-114.

28 Y. Zhang, S. F. Ali, E. Dervishi, Y. Xu, Z. Li, D. Casciano and A. S. Biris, ACS Nano, 2010, 4, 3181-3186.

29 S. Y. Park, J. Park, S. H. Sim, M. G. Sung, K. S. Kim, B. H. Hong and S. Hong, Adv. Mater., 2011, 23, H263-H267.

30 K. T. Lim, H. Seonwoo, K. S. Choi, H. Jin, K. J. Jang, J. Kim, J. W. Kim, S. Y. Kim, P. H. Choung and J. H. Chung, Adv. Healthcare Mater., 2016, 5, 2069-2079.

31 H. Shen, L. Zhang, M. Liu and Z. Zhang, Theranostics, 2012, 2, 283-294.

32 S. Y. Wu, S. S. An and J. Hulme, Int. J. Nanomed., 2015, 10, 924.

33 R. V. Mundra, X. Wu, J. Sauer, J. S. Dordick and R. S. Kane, Curr. Opin. Biotechnol., 2014, 28, 25-32.

34 Z. Liu, J. T. Robinson, X. Sun and H. Dai, J. Am. Chem. Soc., 2008, 130, 10876-10877.

35 J. L. Li, H. C. Bao, X. L. Hou, L. Sun, X. G. Wang and M. Gu, Angew. Chem., Int. Ed., 2012, 51, 1830-1834. 
36 Y. Zhang, T. R. Nayak, H. Hong and W. Cai, Nanoscale, 2012, 4, 3833-3842.

37 L. Wang, C. X. Lu, Y. H. Li, F. Wu, B. Zhao and X. Z. Dong, RSC Adv., 2015, 5, 78660-78668.

38 D. R. Dreyer, S. Park, C. W. Bielawski and R. S. Ruoff, Chem. Soc. Rev., 2010, 39, 228-240.

39 P. Liu, Y. Huang and L. Wang, Mater. Lett., 2013, 91, 125-128.

40 O. Akhavan, E. Ghaderi, S. Aghayee, Y. Fereydooni and

A. Talebi, J. Mater. Chem., 2012, 22, 13773-13781.

41 J. Zhang, H. Yang, G. Shen, P. Cheng, J. Zhang and S. Guo, Chem. Commun., 2010, 46, 1112-1114.

42 X. Shi, H. Chang, S. Chen, C. Lai, A. Khademhosseini and H. Wu, Adv. Funct. Mater., 2012, 22, 751-759.

43 W. Hu, C. Peng, W. Luo, M. Lv, X. Li, D. Li, Q. Huang and C. Fan, ACS Nano, 2010, 4, 4317-4323.

44 J. Kim, Y. R. Kim, Y. Kim, K. T. Lim, H. Seonwoo, S. Park, S. P. Cho, B. H. Hong, P. H. Choung and T. D. Chung, J. Mater. Chem. B, 2013, 1, 933-938.

45 J. Kim, K. S. Choi, Y. Kim, K. T. Lim, H. Seonwoo, Y. Park, D. H. Kim, P. H. Choung, C. S. Cho, S. Y. Kim, Y. H. Choung and J. H. Chung, J. Biomed. Mater. Res., Part A, 2013, 101, 3520-3530.

46 S. Kim, S. H. Ku, S. Y. Lim, J. H. Kim and C. B. Park, Adv. Mater., 2011, 23, 2009-2014.

47 H. S. Jung, T. Lee, I. K. Kwon, H. S. Kim, S. K. Hahn and C. S. Lee, ACS Appl. Mater. Interfaces, 2015, 7, 9598-9607.

48 K. Subramani, S. N. Pandruvada, D. A. Puleo, J. K. Hartsfield Jr and S. S. Huja, Progr. Orthod., 2016, 17, 23.

49 E. Mariscal-Muñoz, C. A. Costa, H. S. Tavares, J. Bianchi, J. Hebling, J. P. Machado, U. H. Lerner and P. P. Souza, Clin. Oral Investig., 2016, 20, 503-511.
50 L. Le Guéhennec, A. Soueidan, P. Layrolle and Y. Amouriq, Dent. Mater., 2007, 23, 844-854.

51 G. Yang, W. Fang, T. Liu, F. He, X. Chen, Y. Zhou and X. Guan, Arch. Oral Biol., 2016, 61, 71-78.

52 K. Y. Hung, S. C. Lo, C. S. Shih, Y. C. Yang, H. P. Feng and Y. C. Lin, Surf. Coat. Technol., 2013, 231, 337-345.

53 K. Fang, W. Song, L. Wang, S. Jia, H. Wei, S. Ren, X. Xu and Y. Song, Int. J. Nanomed., 2014, 9, 4649-4657.

54 R. Olivares-Navarrete, S. L. Hyzy, J. H. Park, G. R. Dunn, D. A. Haithcock, C. E. Wasilewski, B. D. Boyan and Z. Schwartz, Biomaterials, 2011, 32, 6399-6411.

55 J. H. Lee, Y. C. Shin, O. S. Jin, S. H. Kang, Y. S. Hwang, J. C. Park, S. W. Hong and D. W. Han, Nanoscale, 2015, 7, 11642-11651.

56 I. Kanayama, H. Miyaji, H. Takita, E. Nishida, M. Tsuji, B. Fugetsu, L. Sun, K. Inoue, A. Ibara, T. Akasaka, T. Sugaya and M. Kawanami, Int. J. Nanomed., 2014, 9, 3363-3373.

57 H. Aita, W. Att, T. Ueno, M. Yamada, N. Hori, F. Iwasa, N. Tsukimura and T. Ogawa, Acta Biomater., 2009, 5, 32473257.

58 X. Wu and S. Wang, ACS Appl. Mater. Interfaces, 2012, 4, 4966-4975.

59 S. E. Bae, S. H. Bhang, B. S. Kim and K. Park, Biomacromolecules, 2012, 13, 2811-2820.

60 C. Wu, L. Xia, P. Han, M. Xu, B. Fang, J. C. Wang, J. Chang and Y. Xiao, Carbon, 2015, 93, 116-129.

61 W. Zhang, Q. Chang, L. Xu, G. Li, G. Yang, X. Ding, X. Wang, D. Cui and X. Jiang, Adv. Healthcare Mater., 2016, 5, 12991309. 